\title{
Vitamin C Antioxidant Effects in Brain of Albino Mice after Seizures and Status Epilepticus Induced by Pentylenetetrazole (PTZ)
}

\author{
Dina A. Ali*, Mohamed M. Ewais, Cherine M. Khalil, Cherry N. Kamel \\ Department of Pharmacology, Faculty of Medicine, Suez Canal University, Ismailia, Egypt.
}

\begin{abstract}
Aim: Oxidative stress has been implicated in the neurological diseases, one of them is epilepsy. Therefore, this study was conducted to determine the effect of vitamin $\mathrm{C}$ as an acute antioxidant protective treatment of epilepsy in mice. Materials and Methods: Seventy-eight male albino mice were divided into six groups. The first group was a normal control group that received $\mathrm{NaCl}, 0.9 \%$ (i.p.). The second group received PTZ $(65 \mathrm{mg} / \mathrm{kg}$, i.p.) as a single convulsive dose. The third and fourth groups received vitamin C $(500 \mathrm{mg} / \mathrm{kg} / \mathrm{day}$, i.p.) and vitamin C $(1000 \mathrm{mg} / \mathrm{kg}$, i.p.) respectively. The fifth and sixth groups received vitamin C (500 mg/kg/day, i.p.) and vitamin C (1000 mg/kg, i.p.) respectively, then after 30 minutes both received Pentylenetetrazole (PTZ) $(65 \mathrm{mg} / \mathrm{kg}$ i.p.) as a single convulsive dose. Behavioral assessment was done immediately after injections using Racine scale and rotarod tests then after 24 hours, the animals were killed and brain tissue homogenates were prepared to measure lipid peroxide (Malondialdehyde) and catalase activity. Results: Vitamin C showed decreased percentage of seizures, prolonged latency to $1^{\text {st }}$ seizure, improved motor coordination, decreased lipid peroxide level and increased catalase activity. No difference in results between groups received vitamin C $(500 \mathrm{mg} / \mathrm{kg}$, i.p.) or $(1000 \mathrm{mg} / \mathrm{kg}$, i.p.). Conclusion: Vitamin $\mathrm{C}$ was proven to be a potential candidate for decreasing risk of epilepsy.
\end{abstract}

Keywords: Oxidative stress, Epilepsy, MDA, Catalase

\section{Introduction}

Epilepsy is a chronic disorder characterized by recurrent seizures. Seizures are episodes of brain dysfunction resulting from an abnormal discharge of cerebral neurons $^{(1)}$. The prevalence of epilepsy in the general population is 8.2 per 1,000 .lt is estimated that there are 50 to 60 million people with epilepsy worldwide. It is higher in developing countries with a prevalence of 10-12 per 1,000. In Egypt, the prevalence rate was estimated to be 8 per 1,000 and in Upper Egypt the prevalence rate was 12.9 per $1,000^{(2)}$. Unfortunately, only $70 \%$ of patients are effectively treated with currently available antiepileptic drugs (AEDs) ${ }^{(3)}$. Status epilepticus (SE) is a neurologic emergency associated with a mortality rate of $10-12 \%{ }^{(4)}$. This condition is characterized by prolonged or repetitive epileptic discharges, resulting clinically in persistent alterations of normal brain function and cognitive state. Status epilepticus has been previously reported to increase acetylcholine turnover and release in rat brain during development of epilepsy ${ }^{(5)}$. Oxidative stress, which is defined as the overproduction of

*Corresponding Author: dodi_karim@yahoo.com 
free radicals, can dramatically alter neuronal function and was related to epilepsy. It is particularly facilitated in the brain as the brain contains large quantities of oxidizable lipids and metals, and, moreover, has fewer antioxidant mechanisms than other tissues ${ }^{(6)}$.

In the nervous system, the phenomenon known as excitotoxicity has been related to the overproduction of free radicals. Neuronal hyperactivity and/or excite-toxicity may induce an increase in free radical concentration during Pentylenetetrazole (PTZ) induced epilepsy ${ }^{(6)}$.

Antioxidants vary in their ability to quench different free radicals and cellular environments vary with respect to their lipid and aqueous phases. Therefore, supplementation with multiple antioxidants at appropriate doses is essential to prevent or reduce the rate of progression of neurodegenerative diseases. The inhibition of Reactive oxygen species (ROS) accumulation by different antioxidants is specific to the site of ROS generation as well as the antioxidant. This information should be useful for devising new interventions to delay aging or to treat neurodegenerative diseases ${ }^{(7)}$. This work was performed in order to determine the effect of vitamin $C$ as an acute antioxidant protective treatment of epilepsy.

\section{Materials and Methods}

Experimental animals:

Seventy-eight white male albino mice, weighing 20-30 g, were housed in transparent glass cages with free access to food and tap water. The mice were kept under controlled laboratory conditions of normal light-dark cycle and maximum temperature between $25-30^{\circ} \mathrm{C}$.

\section{Behavioral assessment:}

Animals were closely observed for behavioral changes and latency to the development of first tonic-clonic seizure immediately after the injection of PTZ.

\section{Evaluation of the seizures:}

After each injection of PTZ, the convulsive behavior was observed for 30 minutes. The resultant seizures were classified according to Racine's rating scale ${ }^{(8)}$. The mean average score was calculated for each group at the end of the experiment after 24 hours.

Table 1: The rating scale for the evaluation of seizures ${ }^{(8)}$

\begin{tabular}{|l|c|}
\hline Symptoms & Score \\
\hline - No seizure response & 0 \\
- Immobility, eye closure, ear twitching, facial clonus & 1 \\
- Head nodding associated with more severe facial clonus & 2 \\
- Clonus of one forelimb & 3 \\
- Bilateral forelimb clonus without rearing & 3.5 \\
- Bilateral forelimb clonus with rearing & 4 \\
- Falling on a side (without rearing), loss of righting reflex* accompanied by generalized & 4.5 \\
- tonic clonic seizures & 5 \\
\hline
\end{tabular}

* Loss of righting reflex is defined as the inability of the animal to right itself within $30 \mathrm{Sec}$ from a supine Position

\section{Rotarod test}

Groups of mice were trained for 3 days to remain on a rotarod for at least one minute. The animals were excluded and re placed if they failed to do so. A rotor designed in the laboratory was used in the current study. The rotating cylinder had a 4 $\mathrm{cm}$ diameter and the rotation speed was 
set at 80 rounds per minute (RPM). Normally the animals must continually walk forward to avoid falling off the rotarod. After the injection of PTZ, the behavior of animals was evaluated again. Falling time (time starting from putting the animal on the shaft of the rotarod, till it falls to the ground) was measured. The latency to fall in this test represented a measure for motor coordination and motor learning ${ }^{(9)}$. After 24 hours, the animals were killed by decapitation and their brains were dissected for determination of Lipid peroxide (Malondialdehyde 'MDA') and Catalase activity.

\section{Statistical analysis}

All the obtained data were statistically evaluated as appropriate using statistical package for social sciences (SPSS 10).

\section{Results}

Injection of PTZ alone, in the PTZ group, caused a statistically significant development of seizures among 8 of 13 mice
(61.5\%) compared to mice in the (Vitamin C $500 \mathrm{mg}+\mathrm{PTZ}$ ) group and the (Vitamin $\mathrm{C}$ $1000 \mathrm{mg}+\mathrm{PTZ}$ ) group, which developed no seizures. In the (Vitamin C 500mg+PTZ) group and the (Vitamin C 1000mg+PTZ) group, there were significant reduction in the number of mice experienced seizures (3 of 13 mice, $23.1 \%$ and 2 of 13 mice, $15.3 \%$ respectively) compared to the $\mathrm{PTZ}$ group. In the (Vitamin C 50omg+PTZ) group and the (Vitamin C 100omg+PTZ) group, there were a significant reduction in the means seizures score $(2.3 \pm 0.7$ and $1.61 \pm 0.5$ respectively) compared to the PTZ group (3.73 \pm 0.9$)$ (Table 1). In the (Vitamin C 50omg+PTZ) group and the (Vitamin C $1000 \mathrm{mg}+\mathrm{PTZ}$ ), there was a significant prolongation of latency to first seizures compared to the PTZ group. Mean time latency to first seizures in the (Vitamin C 500 $\mathrm{mg}+\mathrm{PTZ}$ ) group and the (Vitamin $\mathrm{C}$ $1000 \mathrm{mg}+\mathrm{PTZ}$ ) was $8.3 \pm 2.5$ minutes and $11 \pm 1.4$ minutes respectively versus $3.2 \pm 0.9$ minutes in the PTZ group (Table 1).

Table 1: Percentage of developed tonic-clonic seizures, the mean seizure (Racine) score, and latency to first seizure among different study groups

\begin{tabular}{|l|ccl|}
\hline $\begin{array}{l}\text { Group } \\
\text { (N/group=13 mice) }\end{array}$ & $\begin{array}{c}\text { Mice developed tonic- } \\
\text { clonic seizures/group n (\%) }\end{array}$ & $\begin{array}{c}\text { Epilepsy score } \\
\text { (Mean } \pm \text { SD) }\end{array}$ & $\begin{array}{l}\text { Latency to 1 } \\
\text { (Mean } \pm \text { SD) }\end{array}$ \\
\hline Control & 0 & ND & ND \\
PTZ & $8(61.6)^{\#}$ & $3.73 \pm 0.9^{\#}$ & $3.2 \pm 0.9$ \\
Vit. C 500 & 0 & $\mathrm{ND}$ & $\mathrm{ND}$ \\
Vit. C 1000 & 0 & $\mathrm{ND}$ & $\mathrm{ND}$ \\
Vit. C $500+$ PTZ & $3(23.1)^{*, \#}$ & $2.3 \pm 0.7^{*, \#}$ & $8.3 \pm 2.5^{*}$ \\
Vit. C $1000+$ PTZ & $2(15.3)^{*, \#}$ & $1.61 \pm 0.5^{*, \#}$ & $11 \pm 1.4^{*}$ \\
\hline
\end{tabular}

$N D=$ not-detected; \#=Statistically significant difference versus control group (P-value $<0.05) ; *=S t a t i s t i c a l l y ~ s i g n i f-$ icant difference versus PTZ group (P-value $<0.05)$

In the (Vitamin C 50omg+PTZ) group and the (Vitamin C 100omg+PTZ) group, there was a significant increase in the mean Rotarod test records $(49.3 \pm 0.5$ seconds and $53.5 \pm 1.3$ seconds respectively) compared to the PTZ group ( $20.3 \pm 0.5$ seconds)
(Table 2). The mean lipid peroxide levels in brain tissue of the (Vitamin C 500mg) group $(31.9 \pm 0.5 \mathrm{nmol} / \mathrm{gm})$ and the (Vitamin C 1000mg) group ( $30.4 \pm 1.2 \mathrm{nmol} / \mathrm{gm})$ were decreased significantly compared to the mean lipid peroxide level in brain tissue of 
the control group $(38.16 \pm 0.9 \mathrm{nmol} / \mathrm{gm})$. Injection of PTZ alone caused a significant increase of the mean lipid peroxide level in brain tissue from $38.16 \pm 0.9 \mathrm{nmol} / \mathrm{gm}$ in the control group to $48.3 \pm 6.3 \mathrm{nmol} / \mathrm{gm}$ in the PTZ group (Figure 1).

Table 2: Rotarod test among study groups

\begin{tabular}{|l|l|}
\hline Group & $\begin{array}{l}\text { Rotarod test (Seconds) } \\
\text { Mean } \pm \text { SD }\end{array}$ \\
\hline Control & $73.1 \pm 0.8$ \\
PTZ & $20.3 \pm 0.5 \#$ \\
Vit. C 500 & $73.2 \pm 1.1$ \\
Vit. C 1000 & $74.3 \pm 0.8$ \\
Vit. C 500 + PTZ & $49.3 \pm 0.5^{*, \#}$ \\
Vit. C 1000 + PTZ & $53.5 \pm 1.3^{*, \#, \bullet}$ \\
\hline
\end{tabular}

*=Statistically significant difference versus PTZ group ( $p$-value < 0.05); \#=Statistically significant difference versus control group ( $p$-value $<0.05$ ); $\bullet=$ Statistically significant difference versus vitamin $C 500+$ PTZ group ( $p$-value $<0.05)$ were increased significantly compared to the mean catalase enzyme level in brain tissue of the control group $(299.8 \pm 5.2 \mu \mathrm{g})$. Injection of PTZ alone caused a significant decrease of the mean catalase enzyme level in brain tissue from $299.8 \pm 5.2 \mu \mathrm{g}$ in the control group to $175.2 \pm 24.7 \mu$ g in PTZ group (Figure 2)

\section{Discussion}

In the current study, the major aim was to determine the effect of vitamin $C$ as an acute antioxidant protective treatment of epilepsy. The PTZ mouse model of seizure was used in order to establish whether epileptic seizures lead to increased oxidative stress, and to explore the possibility that Vitamin $C$ inhibits convulsions and attenuates oxidative stress in mice. Previously it has been reported that vitamin $C$, as comThe means catalase enzyme levels in brain tis- pared to other antioxidant drugs, exert po-
sue of (Vitamin C $500 \mathrm{mg}$ ) group $01.8 \pm 50.7 \mu \mathrm{g}$ ) tent anticonvulsant and neuroprotective and (Vitamin C 100omg) group (621.8 $\pm 52.8 \mu \mathrm{g})$ effects $^{(10)}$.

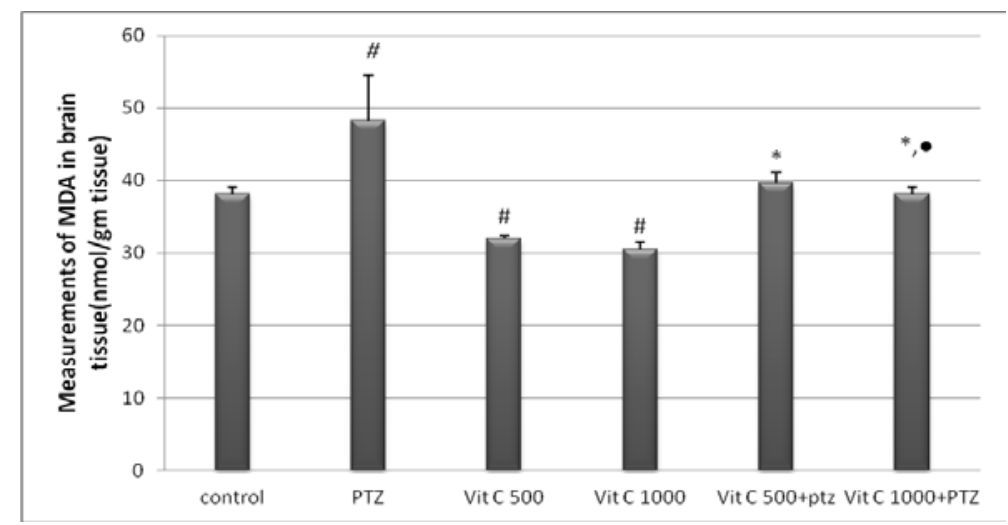

Figure 1: Lipid peroxide (MDA) levels in brain tissue from different experimental groups $(*=$ Statistically significant difference versus PTZ group ( $p$-value < 0.05); \#=Statistically significant difference versus control group ( $p$ value $<0.05$ ); $\bullet=$ Statistically significant difference versus vitamin $C$ $500+P T Z$ group $),(p$-value $<0.05)$
It is feasible that vitamin $C$ can exert its neuroprotective role as a potent scavenger of oxygen free radicals ${ }^{(11)}$. Vitamin $C$ administration, 30 min before Pilocarpine inject tions, increased the latency to the onset of the first seizure in $92 \%$ of tested animals and latency of the status epilepticus in 95\% in tested animals ${ }^{(12)}$. Similarly the antioxidant vitamin $C$ can effectively reduce the severity of PTZ-induced brain injury in adult rats $^{(13)}$. Xianchun et al. used acute PTZ model in mice ( $80 \mathrm{mg} / \mathrm{kg}$ i.p.) and used kindled PTZ model in mice ( $25 \mathrm{mg} / \mathrm{kg}$ i.p.) and $(45 \mathrm{mg} / \mathrm{kg}$ i.p.). Both recorded latency to $1^{\text {st }}$ seizure and seizure score (Racine score) for 30 minutes $^{(14)}$. 


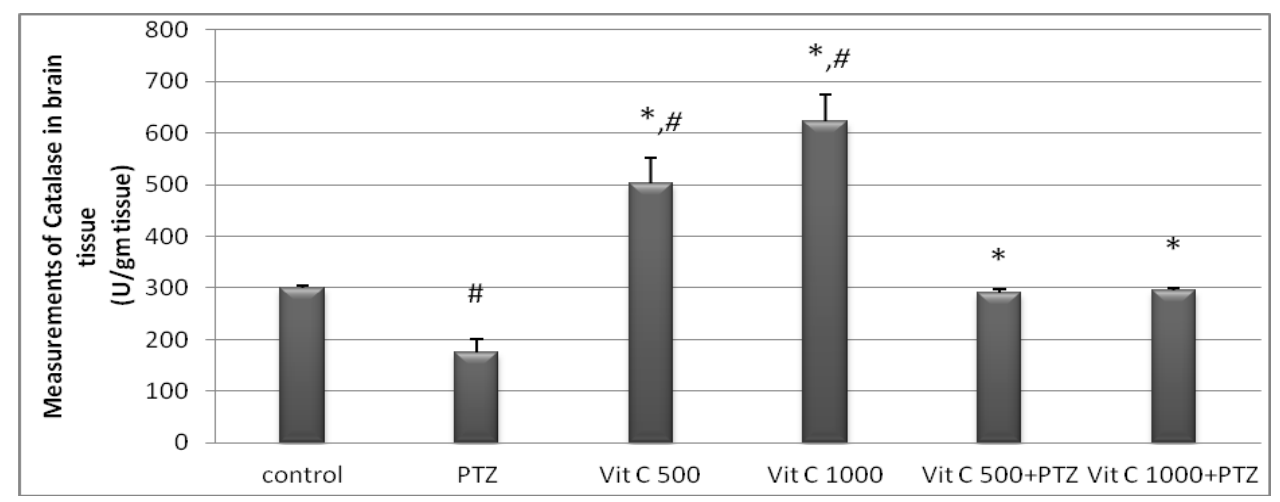

Figure 2: Catalase activity in brain tissue among different study groups ${ }^{*}=$ Statistically significant difference versus PTZ group $p$-value<0.05); \#= statistically sig-nificant difference versus control group ( $p$ -

Vitamin C was tested in acute models of epilepsy induced by PTZ. In the PTZ group, animals treated with vehicle followed by subcutaneous injection of PTZ. All animals had severe seizures. The mean latency to generalized seizure was $5.7 \pm 0.7 \mathrm{~min}$ of the remaining animals, 1 had a seizure score of 3 and the remaining were scored 4.5 or 5 . All of the animals treated with $250 \mathrm{mg} / \mathrm{kg}$ i.p. Vitamin $C$ treated animals had a seizure score of 1,3 and 4.5 and none of them had scored 5 with an increase in latency to first seizure. This came in line with the results of this current study ${ }^{(15)}$. In the current study, regarding the (lipid peroxide) MDA levels in brain tissue; the PTZ group exhibited an increase in MDA level versus the control group, while pretreatment with vitamin $C$ before PTZ injection exhibited a decrease in the MDA level versus PTZ group. Regarding catalase level, the PTZ group showed decreases in catalase level compared to control group, while pretreatment with Vita$\min C$ caused an increase in catalase level compared to PTZ group. In addition, catalase level increased in groups received vitamin $\mathrm{C}$ alone compared to control group.

Membrane lipids, which contain unsaturated fatty acids are particularly sensitive to oxidative stress and peroxidation of the membrane lipids leads to a disturbance of the membrane integrity ${ }^{(16)}$. The damaged membranes are repaired and one important repair mechanism is reacylation of the phospholipids in the membrane. There are reports that lipid peroxidation inhibits this reacylation process. The nervous system is more susceptible to the damaging effect of oxidative stress, due to the high content of polyunsaturated fatty acids that are susceptible to lipid peroxidation. It receives a large percentage of oxygen and is relatively deficient in antioxidant enzymes. It has been suggested that an increase in the free radicals may cause neuronal degeneration through peroxidation and decrease in the reduced glutathione levels ${ }^{(17)}$. Xavier et al. proved that treatment with a single dose of Pilocarpine produced a decrease in hippocampal catalase activity in comparison with the control group. The catalase activity, quantified in animals treated only with Vitamin C 250 showed an increase in relation to control group. The group pretreated with Vit C $250 \mathrm{mg} / \mathrm{kg}$ 3omin before pilocarpine showed a decrease in catalase activity compared to the group treated only with Pilocarpine. This study was conducted on adult Wistar rats using Pilocarpine for induction of epilepsy ${ }^{(10)}$. The exact mechanisms through which Vitamin $C$ shows its neuro-protective ef- 
fects are not fully understood, however, Lucia et al. showed that pretreatment of Vitamin C plus PTZ have neuro-protective actions. Vitamin C pretreatment decrease hippocampal lipid peroxidation content by increasing catalase activity, indicative of a possible antioxidant effect ${ }^{(17)}$.

\section{References}

1. Fisher RS, Van Emde Boas W, Blume W, Elger C, Genton P, Lee P, Engel J Jr. Epileptic seizures and Epilepsy: definitions proposed by the International League Against Epilepsy (ILAE) and the International Bureau for Epilepsy (IBE). Epilepsia 2005; 46 (4): 470-472.

2. Kandil MR, Ahmed WM, Sayed AERM, Hamed SA. Pattern of epilepsy in childhood and adolescent. A hospital based study. Afr J Neurol sci 2007; 26(1): 3344.

3. Sills GJ, Rundfeldt C, Butler E, Forrest G, Thompson GG, Brodie MJ. A neurochemical study of the novel antiepileptic drug retigabine in mouse brain. Pharmacol Res 2009; 42(6): 553-557.

4. Treiman DM. Electroclinical features of Status Epilepticus. J Clin Neurophysiol 1995;12 (4):343-362.

5. Aicardi J and Chevrie JJ. Consequences of status epilepticus in infants and children. Adv Neurol 1983; 34:115-125.

6. Freitas RM, Vasconcelos SM, Souza FC, Viana GS, Fonteles MM. Oxidative stress in the hippocampus after Pilocarpine induced status epilepticus in wistar rats. FEBS j 2005; 272 (6): 1307-1312.

7. Liu Y. \& Schubert DR. The specifity of neuroprotection by antioxidants. J Biomed Sci 2009, 16:98.

8. Racine RJ. Modification of seizure activity by electrical stimulation. II. Motor seizure. Electroencephalog Clin Neurophysiol 1972 ;32 (3): 281-294.
9. Borowicz KK, Łuszczki J, Swiader M, Kleinrok Z, Czuczwar SJ. Influence of sexual hormone antagonists on the anticonvulsant action of conventional antiepileptic drugs against electricallyand pentylenetetrazole induced seizures in mice. Eur Neuropsychopharmacol 2004; 14 (1): 77-85.

10. Xavier SM, Barbosa CO, Barros DO, Silva RF, Oliveira AA, Freitas RM. Vitamin $C$ antioxidant effects in hippocampus of adult Wistar rats after seizures and status epilepticus induced by Pilocarpine. Neurosci Lett 2007; 420 (1): 76-79.

11. Peng $\mathrm{Y}, \mathrm{K}$ wok KH, Yang $\mathrm{PH}, \mathrm{Ng} \mathrm{SS}$, Liu J, Wong OG, He ML, Kung HF, Lin MC. Ascorbic acid inhibits ROS production, NF-kappa B activation and prevents ethanol-induced grow-th retardation and microencephaly. Neuropharmacology 2005; 48 (3): 426-434.

12. Santos IM, Freitas RL, da Silva EP, Feitosa CM, Saldanha GB, Souza GF, Tomé Ada R, Feng D, de Freitas RM. Effects of ubiquinone on hydroperoxide concentration and antioxidant enzymatic activities in the rat hippocampus during Pilocarpine-induced seizures, Brain Res 2010; 13(15): 33-40.

13. Naseer MI, Ullah I, Ullah N, Lee HY, Cheon EW, Chung J, Kim MO. Neuroprotective effect of vitamin $C$ against PTZ induced apoptotic neurodegeneration in adult rat brain. Pak J Pharm sci 2011; 24 (3): 263-268. 
14. Li $X$, Yang Q, Kuang $\mathrm{H}$, Jiang $\mathrm{N}$, Hu Y.Involvement of Scn1b and Kcna1 ion channels in audiogenic seizures and PTZ-induced epilepsy. Epilepsy Res 2005; 66 (1-3): 155-163.

15. Xu K and Stringer JL. Antioxidants and free radical scavengers do not consistently delay seizure onset in animal models of acute seizures. Epilepsy Behav 2008;13 (1) :77- 82.

16. Pandey MK, Mittra P, Maheshwari PK. The Lipid Peroxidation Product as a Marker of Oxidative Stress in Epilepsy. J Clin Diagn Res 2012; 4: 590-592.

17. Santos LF, Freitas RL, Xavier SM, Saldanha GB, Freitas RM. Neuroprotective actions of vitamin $C$ related to decreased lipid peroxidation and increased catalase activity in adult rats after Pilocarpine -induced seizures. Pharmacol Biochem Behav 2008; 89 (1):1-5. 